\title{
Women's Labor force Participation in Sri Lanka: An Inquiry into the Factors Influencing Women's Participation in the Labor Market
}

\author{
Wanninayake M. Semasinghe
}

\begin{abstract}
The main objective of this study was to identify the contributory factors that obstruct women from entering the labor market at the micro level. The study was based mainly on the mixed method approach. A sample survey method was employed to collect data in order to achieve the main objective while data generated by Quarterly Labor Force Surveys were employed to achieve the other objective.

As analysis revealed involvement in household activities is the major factor common to all three sectors. Other factors that were identified were engagement in studies, voluntarily abstaining from working in order to enjoy leisure, sufficiently high level of household income to preclude the need for an additional income, bad environment in the work place, unfavorable working conditions, socio-cultural constraints, physical illness/disability, having retired, low wages, family decision, lack of employment opportunities, low education level, backward attitudes, lack of awareness about the employment opportunities and lack of skills to cope with available opportunities. Among these, the first three are common to the urban and rural sectors while the last four factors are specific to the estate sector.
\end{abstract}

Index Terms-Economic development, female labor force participation, social development, Sri Lanka, U-hypothesis.

\section{INTRODUCTION}

Labor force participation means the active engagement or willingness of people of working age to engage in economic activities included in the System of National Accounts (SNA) The size of the labor force in a country depends on the number of individuals of working age participating in the labor market. The proportion of economically active persons of a country relative to the total working age population is expressed as the labor force participation rate (LFPR). Engagement in any activity for pay, including self-employment that produces some product or service for the market or for consumption within the household is considered as labor force participation but not the services such as looking after own child, general housework etc. Further, individuals who are not employed but are willing to work and actively seeking employment in SNA activities are also included [1]. As this includes all economically active individuals, it indicates the relative size of the labor pool available to engage in the production of goods and services

Manuscript received April 25, 2016; revised June 29, 2016. This work is supported by the Faculty Development Fund of the Faculty of Social Sciences.

Wanninayake M. Semasinghe is with the Department of Economics, University of Kelaniya, P.O. Box, 11600, Sri Lanka (e-mail: sema23@kln.ac.1k).
(ILO - http://www.ilo.org/empelm/what/WCMS_114240 / lang--en/index.htm accessed January, 2016). Full utilization of all resources available in a country is critical to achieve and sustain a high level of growth in that country. Labor force participation is one of the crucial areas to which much attention must be paid in this regard. The higher the labor force participation rate, the higher the percentage of the country's working age population involved in the labor market. In fact, the labor force participation rate is not only an economic indicator but also an attribute that links with many other aspects of human life, particularly in the less developed countries.

Though female labor force participation (FLFP) is generally lower compared to that of the males in all countries, it is unusually low in some developing countries in absolute terms as well as when compared to the EU and OECD standard $^{1}$. Low FLFP means that a substantial proportion of working age females is not contributing to the national economy. The low rate of FLFP reflects to some extent the country's labor related economic imbalance as well as its social and cultural norms. Further, it mirrors the gender inequality in employment opportunities and to the state of the peoples' participation in economic activities. In fact, gender inequality continues to be one of the key socioeconomic concerns of many international organizations, social activists, women's movements, NGOs etc. over the decades, all of which emphasize the demand that equal opportunities should be available to women. As a consequence, national policies have been put in effect in many developing countries giving priority to promote gender equality so as to empower women. Female labor force participation rate of a country is one of the key indicators that reflect women's contribution to the economy. If the rate is close to that of the males' participation rate, then women can be said to have opportunities equal to that of men in contributing to the economy.

In the case of Sri Lanka, the female labor force participation rate is much lower in both absolute as well as relative terms when compared to the countries in the region and many other distant but comparable countries. By 2014 the rate was around 35 present. This means that only about 35 out of every 100 women in the working age category participated in the labor market. There are considerable sector differences in the FLFP of the country. Although labor force participation of women in the estate sector is as high as 52 per cent, it is only 35 per cent and 30 per cent respectively in the rural and urban sectors [2]. In contrast to the FLFP, male labor force participation (MLFP) in the country is as 
high as in other countries. In fact, it has been twice as high as the FLFP rate from the time records have been kept. As the World Bank points out Sri Lanka reports the 28th largest gender gap in labor force participation. Teignier and Cuberes [3] have estimated that the loss of per capita income due to gender gaps in employment, self-employment, labor force participation and wages is 20 per cent.

During the past two or three decades Sri Lanka has achieved remarkable progress in social development, accompanied by modest economic growth. Gender inequality in many fields including access to education, health, employment opportunities etc. has declined significantly and many other aspects of social development relating to females have also improved. Moreover, there is no significant discrepancy in educational attainment between younger men and women; the fertility rate is significantly low. As reported by the Global Gender Gap Report (2010) of the World Economic Forum, Sri Lanka is among the top 20 countries in the world in gender equality. Meanwhile, Sri Lanka is at a transitional stage of economic development with a shrinking agricultural sector and gradually rising industrial and service sectors. Under this circumstance, the FLFP is expected to increase in keeping with the traditional U-hypothesis. Amidst these favorable circumstances it is puzzling to observe that the FLFP rate is as low as 35 percent. In fact, this rate is comparatively much lower than what one would expect given the high level of women's educational attainments and progressive achievements in other aspects of social development. Although Sri Lanka is ahead of other South Asian countries in terms of human and social development, when it comes to female labor force participation it surprisingly ranks at the same level as other South Asian countries. In this context, the question that arises is why the FLFP rate is very low even though the necessary conditions that stimulate female labor force participation have gradually improved over the past two-three decades? Hence, this study mainly focuses on identifying the factors that obstruct women from entering the labor market at the micro level. In this endeavor an attempt will be made to examine whether there are any sector differences in these factors. In addition, the study will attempt to quantify the impact of key determinants on FLFP in Sri Lanka at the macro level.

\section{RESEARCH APPROACH AND DATA}

This study is based mainly on the mixed method approach. This is because in order to attain the desired objectives both qualitative data as well as quantitative data are required. Thus, qualitative methods as well as quantitative methods were used to collect the data to be analyzed.

Although systematic data on the labor force are available from 1946 onwards as generated by the various census and surveys conducted from time to time, continuous time series data are available only from 1990 with the introduction of the Quarterly Labor Force Survey (LFS). Although these data are not strictly comparable mainly due to the differences in coverage, definitions and assumptions, they can be utilized to understand the general trends and scale of labor force related

${ }^{1}$ FLFPR in many OECD countries is around 70 per cent.

\section{phenomena.}

An empirical model was formulated to identify the impact of selected macro level factors on women's labor force participation. Based on the literature and the data availability, the following factors, viz. education level of female (ED), fertility rate (FR), urbanization (UR), GDP growth rate (GDP), female unemployment rate (UN) and male labor force participation rate (MLFP) were selected as explanatory variables.

The following model was then formulated under the assumption that the relationship between FLFP and other variables is linear:

$F L F P_{t}=\beta_{0}+\beta_{1} E D_{t}-\beta_{2} F R_{t}+\beta_{3} U R_{t}+\beta_{4} G D P_{t}+\beta_{5} U N_{t}+\beta_{6} M L F P_{t}+\varepsilon_{t}$

This model is to be fitted with the secondary data collected from the Labor Force Surveys (LFSs) of the Department of Census and Statistics (DCS), and from the reports of the Central Bank of Sri Lanka (CBSL). In order to identify the factors that prevent women from participating in the labor force, a sample survey was carried out. Sampling design was based on the quota sampling method and the overall sample size was 250 units. Sampling units were the women between 15 and 64 years of age who were not participating in the labor market. One hundred women from the urban sector, one hundred from the rural sector and fifty from the estate sector were selected purposively. A structured questionnaire was used to collect data from the selected sampling units.

\section{Determinants OF FeMAle LABOR ForCE PARTICIPATION: A LITERATURE REVIEW}

A substantial volume of literature on the empirical and theoretical analysis of the trends, determinants, obstacles etc. of the labor force participation was studied employing various methodologies and different datasets. Among those, interest was laid mainly on the examination of the relationship between female labour force participation (FLFP) and economic development as dealt with in the pioneer works of Mincer [4] and Cain [5]. This relationship is described by the so-called U-hypothesis. According to this hypothesis, the FLFP rate is high during the initial phase of economic development mainly in agrarian societies due to the close linkage between households and the production process. Although the fertility rates are still high women work in family farms or household enterprises while engaging in childcare. When the economy moves from agricultural to industrial and service based formal economy the FLFPR falls. This is because in these types of economy the employment opportunities for women are fewer. At the same time, social customs and employer preferences hindered women's involvement in the manufacturing sector [6]. Moreover, the generally low level of education of females, inability to work with childrearing burdens and the socio-cultural restriction on females from working outside the home prevented them from entering the labor market. Consequently, females were unable to benefit from the emerging opportunities in the formal sector [7]. This decrease in the FLFP rate was taking place only up to a certain level of economic development. In 
the latter stage of development, employment opportunities for females increased with the structural changes of the economy as well as the impact of some other factors including the rise in female education and declining fertility, causing an increase in FLFP again. This increase is reinforced by the expansion of post-primary education among women, emergence of white-collar jobs, decline in fertility, increase in part time job opportunities, and better access to childcare facilities [1], [7]. A considerable number of studies including those by Boserup [8], Goldin [7], Mammen and Paxson [9], Mincer [10], Pampel and Tanaka [11], Schultz [12], and Tam [12]-[13] have been carried out to examine this relationship.

As the literature reveals, FLFP is determined by a number of factors. Among those some factors are common to all countries but some are country-specific. GDP growth rate, religious, social and cultural norms, family income, fertility rate etc. can be identified as the common factors that determine the rate of FLFP in any country. Furthermore, female education, state of overall economic and labor market conditions such as the level of urbanization, employer preferences and the unemployment rate play important roles in determining the number of females entering the labor market [4], [6]-[8], [13], [14], [16], [18]-[20],. Tradition, culture and household responsibilities held by women also restrict their participation in the labor market [6]. Thus, the analysis reveals that social institutions, religious attitudes, social class etc. exert a strong influence on females' labor force participation in India [21]. In some households the question of whether a woman in the family should enter the labor market is a decision that is made collectively by the family [22], [23]. In making this decision, they take into account personal factors, household characteristics as well as economic factors. Further education and training opportunities also cause delays in women entering the labor market [14]. In addition to the above factors, as OECD evidence discloses, the policies on promoting flexibility of working hours, the system of family taxation, and the support given to families in the form of childcare subsidies, childcare benefits, and paid parental leave also affect the decision [15]. As per the Department of Census and Statistics' (DCS) findings, the main reason for the low female labor force participation in Sri Lanka is involvement in household activities. In addition, engaging in studies, suffering physical illness, having retired and being feeble due to old age have also kept females out of the labor force. Moreover, as has been reported by the Central Bank of Sri Lanka (CBSL), unavailability of safe accommodation and transportation to and from work, difficulties in adhering to work time slots and inability to find employment after a break are among the major reasons for low female labor force participation in the country [2].

\section{DISCUSSION AND CONCLUSIONS}

The main focus of this study was to identify the causes behind the low level of labor force participation of Sri Lankan females, both at the macro level and micro level. The model formulated in Section 2 to measure the impact of macro level factors on FLFP was fitted with data pertaining to the period from 1990 to 2014 . The estimated model is given in Table I.

TABLE I: ESTIMATED REGRESSION MODEL

\begin{tabular}{|l|r|r|r|r|}
\hline \multicolumn{1}{|c|}{ Model } & \multicolumn{1}{c|}{ B } & \multicolumn{1}{c|}{ Std. Error } & \multicolumn{1}{c|}{ t } & \multicolumn{1}{c|}{ Sig. } \\
\hline (Constant) & -6.745 & 137.790 & -0.049 & 0.961 \\
\hline FER & 1.658 & 4.437 & 0.374 & 0.713 \\
\hline UNEMP & -0.238 & 0.124 & -1.920 & 0.069 \\
\hline URBAN & 2.115 & 7.428 & 0.285 & 0.779 \\
\hline GDP & 0.101 & 0.138 & 0.732 & 0.472 \\
\hline
\end{tabular}

The model does not establish any statistically significant relationship between FLFP and the other factors except unemployment among females (UNEMP). The coefficient of UNEMP is significant at 10 per cent significance level and reveals that there is a negative relationship between FLFP and UNEMP. This means that when unemployment among females increases, FLFP decreases. This is theoretically correct. The coefficients of other factors are significant neither theoretically nor statistically. This means that those factors do not affect significantly the variability of FLFP. In fact, this is an unusual outcome. Poor quality of data might be the reason for this outcome. The definitions, methodology and coverage of the surveys that generated these data are not consistent. They differ from survey to survey and time to time.

The sample survey revealed that the number of women who have never participated in the labor market is very few. Many have been actively engaged in economic activities for some years and left due to various reasons such as marriage, having children, ill health, and work place difficulties. As the survey data reveals, a range of factors including economic, socio-cultural, and labor market conditions has contributed to keep women out of the labor market. Although there are some sector specific factors, many factors are common to all three sectors, i.e. urban, rural and estate sectors. Other than the percentage of women belonging to each category, the causes of urban, rural and estate sector non-participation are very similar. (i) Involvement in household activities is the major factor common to the three sectors, though responsibilities of females within the household differ among sectors. Generally the responsibilities include childcare, food preparation, helping with children's education, upkeep of houses, looking after the elderly and disabled members of the family, etc. Other causes identified were (ii) involvement in studies, (iii) voluntarily turning down work to enjoy leisure, (iv) sufficiently high level of income of the household that precludes the need for additional income, (v) bad environment in the work place, (vi) unfavorable working conditions, (vii) socio-cultural norms, (viii) physical illness/disability, (ix) retirement, (x) low wages, (xi) family decision, (xii) low education, (xiii) lack of information, (xiv) backward attitudes (xv) lack of awareness of available employment opportunities, and (xvi) lack of skills to cope with existing opportunities. Among these (ii), (iii) and (iv) are common to the urban and rural sectors while the last five are specific to the estate sector.

Further, among these (ii), (iv), (xii) and (xvi) are economic factors while (i), (iii), (vii) (xi), and (xiii) are socio-cultural factors. Factors (v), (vi), (x) and (xiv) are labor market 
related factors and (viii) and (ix) are general factors.

These factors should be considered carefully and strong efforts made to overcome them in a timely manner in order to encourage women to participate more vigorously in the national economy through increasing the rate of female labor force participation. Among these, labor market related factors can be influenced effectively through sound policy measures within a relatively short period of time. However, as socio-cultural factors are rather sensitive issues being bound with the traditional lifestyle, these should be addressed in a very prudent manner.

\section{REFERENCES}

[1] I. Gaddis and K. Stephan, Economic Development, Structural Change and Women's Labor Force Participation, Reexamination of the Feminization $U$ Hypothesis, Department of Economics, the New School for Social Research, 2012.

[2] CBSL, Annual Reports in Various Years, Central Bank of Sri Lanka.

[3] M. Teignier and C. David, "Aggregate costs of gender gaps in the labor market: A quantitative estimate," University of Barcelona, Working Paper E14/308. 2014, November.

[4] J. Mincer, "Labor force participation of married women: A study of labor supply," Aspects of Labor Economics, Universities National Bureau Committee for Economic Research. Princeton, NJ: Princeton University Press, 1962

[5] G. G. Cain, Labor Force Participation of Married Women, Chicago: University of Chicago Press, 1966.

[6] S. Tsani, L. Paroussos, C. Fragiadakis, I. Charalambidis, and P. Capros, "Female labor force participation and economic development," Economic and Social Development of the Southern and Eastern Mediterranean Countries, Springer International Publishing Switzerland. 2015.

[7] C. Goldin, The U-shaped Female Labor Force Function in Economic Development and Economic History, The University of Chicago Press, Chicago, 1995

[8] E. Boserup, Women's Role in Economic Development, George Allen and Unwin, London, 1970.

[9] K. Mammen and C. Paxson, "Women's Work and Economic Development," Journal of Economic Perspectives, vol. 14, no. 4, pp. $141-164,2000$

[10] J. Mincer, "Inter-Country Comparison of Labor Force Trends and Related Developments: An Overview," Journal of Labor Economics, vol. 3, no. 1, Part 2, 1985.

[11] F. C. Pampel and K. Tanaka, "Economic Development and Female Labour Force Participation: A Reconsideration," Social Forces, vol. 64, no. 3, pp. 599-619, 1986.

[12] T. P. Schultz, "International differences in labor force participation in families and firms," Economic Growth Center Working Paper, no. 634 Yale University, New Haven, 1991.

[13] H. Tam, "U-shaped female labor participation with economic development: some panel data evidence," Economics Letters, vol. 110 no. 2, pp. 140-142, 2011.

[14] I. De Silva, G. Abeywickrama, and K. D. Wijesinghe, "Projection of population, labor force and its female component in Sri Lanka," Economic Review, vol. 38, October/ November, 2012.

[15] F. Jaumotte, (2003). Female Labour Force Participation: Past Trends and Main Determinants in OECD Countries. OECD Economics. Department Working Papers. No. 376. [Online]. Available: file://C:/Users/DR5378 1.SEM/AppData/Local/Temp/SSRN-id2344 556.pdf
[16] A. P. Kottis, "Shifts overtime and regional variation in women's Labour force participation rates in a developing economy," Journal of Development Economics, vol. 33, no. 1, pp. 117-132, 1990.

[17] J. P. Smith and M. P. Ward, "Time-series growth in the female labor force," Journal of Labor Economics, vol. 3, no. 1, Part 2: Trends in Women's Work, Education, and Family Building, pp. S59-S90, Jan. 1985.

[18] A. Tansel, "Wage employment, earnings and returns to schooling men and women in Turkey," Economics of Education Review, vol. 13, no. 4, pp. 305-320, 1991

[19] A. Tansel., "Self-employment, wage employment and return to education for urban men and women in Turkey," Ed. T. Bulutary, Education and the labor market in Turkey, State Institute of Statistics Publication. Ankara, 1996.

[20] A. Tansel. (2001). Economic development and female Labor force participation in Turkey: Time-series evidence and cross-province estimates. [Online]. Available: http://citeseerx.ist.psu.edu/viewdoc/download?doi=10.1.1.462.9820\& rep=rep $1 \&$ type $=$ pdf

[21] P. Sorsa, J. Mares, M. Didier, C. Guimaraes, M. Rabate, G. Tang, and A. Tuske. (2015). Determinants of the Low Female Labour Force Participation in India. [Online]. Available: http://www.oecd.org/ officialdocuments/publicdisplaydocumentpdf/?cote=ECO/WKP\%282 $015 \% 2925 \&$ docLanguage $=$ En

[22] G. S. Becker, A Treaties on the Family, Enlarged edition, Harvard University Press, 1991.

[23] M. R. Killingsworth, Labor Supply, Cambridge University Press, Cambridge, 1983.

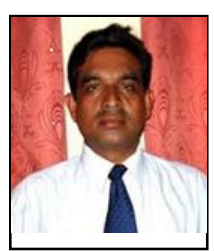

W. M. Semasinghe was born in Kurunegala, Sri Lanka He graduated from the University of Kelaniya, Sri Lasnka in 1991 with a B.A. (Hons.) first class degree in economics. He secured a master of arts (MA) degree in economics in 1998 and a postgraduate diploma in social statistics in 2005 from the University of Sri Jayawardenepura, Sri Lanka. In 2009, he obtained his $\mathrm{PhD}$ degree in economics from the University of Kelaniya. His $\mathrm{PhD}$ degree program was funded by the Sida/SAREC Project and he engaged in research studies as a part of his $\mathrm{PhD}$ degree in Gothenburg University, Sweden. In addition to that he has attended several training programs including Regional Course in Environmental and Natural Resource Economics, AIT, in Thailand in 2003 and Summer School in Social Science Research Methods, at the African Doctoral Academy, Stellenbosch University, South Africa in 2012.

He has been teaching economics and social statistics at the University of Kelaniya, Sri Lanka for over 23 years and currently serves as a Senior Lecturer (Grade 1) in the Department of Economics. His research interests lie in the fields of rural poverty and development.

He has published a few books on Economics and a number of research articles relating to the area of rural poverty and development in Sri Lanka His latest book is Public Welfare Policies and Multidimensional Poverty in Sri Lanka: An Application of Capability Approach published in 2015 by Sarasavi Publishers, Nugegoda, Sri Lanka. In addition, the articles titled "Economic and Social Cost of Fertilizer Subsidy on Paddy Farming in Sri Lanka," International Journal of Science and Research (IJSR), Vol. 3. Issue 10, October 2014, pp.1261-1267 and "Multidimensionality of Urban Poverty: An Inquiry into the Critical Factors affecting the Well-being of the Urban Poor in Sri Lanka," International Journal of Economics, Commerce and Management, United Kingdom, Vol. III, Issue 11, November 2015, pp. 363-374 are also credited to his name. 